\title{
$S$-wave in lead III is helpful for the early detection of bupivacaine-induced cardiac depression in dogs
}

\author{
[L'onde S en D III est utile pour la détection précoce de la dépression myocardique \\ induite par la bupivacaïne chez les chiens]
}

Jin-Tae Kim MD, ${ }^{*}$ Ji-Yeon Jung MD, ${ }^{*}$ Chul-Woo Jung MD, ${ }^{*}$ Ji-Ae Kim MD, $†$ Hyun-Sung Cho MD, $†$ Kook-Hyun Lee MD*

Purpose: Unintentional intravascular bupivacaine injection is known to be associated with treatment-resistant cardiovascular collapse. Therefore, it is important for safe anesthetic management to establish an early sign of bupivacaine-induced cardiac depression with available monitoring. We hypothesized that bupivacaine induced-cardiac depression in dogs could be detected early by analyzing the electrocardiogram (ECG). We performed this study to investigate changes of ECG and ultimately find a variable reflecting cardiac output (CO) changes in dogs with bupivacaine-induced cardiac depression.

Methods: Bupivacaine was infused into pentobarbital-anesthetized dogs $(n=9)$ at a rate of $0.5 \mathrm{mg} \cdot \mathrm{kg}^{-1} \cdot \mathrm{min}^{-1}$ for $30 \mathrm{~min}$. $\mathrm{R}$-wave, S-wave and T-wave amplitudes in leads I, II and III were measured every five minutes after the start of bupivacaine infusion, and electrical axes of the heart were calculated at each time. The PR interval, QRS complex duration and corrected QT interval were also measured. $\mathrm{CO}$, mean arterial blood pressure and heart rate were recorded at five-minute intervals. The relationships between CO and ECG wave parameters and of CO vs the hemodynamic variables were compared by correlation coefficients and regression analysis.

Results: The electrical mean axis of the heart was deviated to the left by the bupivacaine infusion. S-wave in lead III increased approximately twice within the first five minutes and showed the closest correlation with $\mathrm{CO}(r=0.75 \mathrm{I}, P<0.00 \mathrm{I})$ during 30 min bupivacaine infusion.

Conclusion: Close monitoring of an ECG, and especially the Swave amplitude in lead III can be helpful for the early detection of bupivacaine-induced cardiac depression in dogs.
Objectif : L'injection intravasculaire accidentelle de bupivacaïne est associée à un collapsus cardiovasculaire rebelle au traitement. Pour la sécurité de l'anesthésie, il faut donc définir, avec le monitorage disponible, un signe précoce de dépression myocardique induite par la bupivacaïne. Nous avons pensé que cette dépression pouvait être détectée tôt chez des chiens en analysant l'électrocardiogramme (ECG). Nous voulions explorer les modifications de l'ECG et, à la limite, trouver une variable montrant des changements de débit cardiaque (DC) chez des chiens atteints de dépression myocardique induite par la bupivacaïne.

Méthode: La bupivacaïne est perfusée chez des chiens anesthésiés au pentobarbital $(n=9)$ à $0,5 \mathrm{mg} \cdot \mathrm{kg}^{-1} \cdot \mathrm{min}^{-1}$ pendant 30 min. L'amplitude des ondes R, S et T en D I, D II et D III est mesurée cinq minutes après le début de la perfusion et les axes électriques du cœur calculés à chaque fois. L'intervalle $P R$, la durée du complexe QRS et l'intervalle QT corrigé sont aussi mesurés. Le $D C$, la tension artérielle moyenne et la fréquence cardiaque sont notés aux cinq minutes. La relation entre le $D C$ et les paramètres des ondes de l'ECG et entre le DC et les variables hémodynamiques est comparée par les coefficients de corrélation et l'analyse de régression.

Résultats : L'axe électrique moyen du cœur a été dévié vers la gauche par la perfusion de bupivacaïne. L'onde $S$ en D III a augmenté approximativement du double pendant les cinq premières minutes et a montré la relation la plus étroite avec le DC $(r=$ $0,75 I, P<0,00 I)$ pendant 30 min de perfusion de bupivacaïne.

Conclusion: La surveillance étroite d'un ECG, spécialement de l'amplitude de l'onde S en D III, peut hâter la détection de la dépression myocardique induite par la bupivacaïne chez les chiens.

From the Department of Anesthesiology and Pain Medicine, Seoul National University College of Medicine; ${ }^{*}$ and Samsung Medical Center, $†$ Sungkyunkwan University, Seoul, Korea.

Address correspondence to: Dr. Kook Hyun Lee, Department of Anesthesiology, Seoul National University College of Medicine, \#28,

Yongon-Dong, Chongno-Gu, Seoul, Korea 110-744. E-mail: leekh@plaza.snu.ac.kr

This article was supported by the grant of the Seoul National University Hospital (21-2004-012-0).

This article has no financial relationship with any pharmaceutical companies.

Presented in part at the American Society of Anesthesiologist annual meeting, Las Vegas, October 27, 2004.

Accepted for publication January 28, 2005.

Revision accepted April 5, 2005. 
$\mathrm{U}$ NINTENTIONAL intravascular injection or large doses of bupivacaine can provoke serious cardiovascular collapse. ${ }^{1,2}$ Furthermore, bupivacaine-induced cardiotoxicity has been known to be difficult to treat. ${ }^{3,4}$ Therefore, early recognition of the signs of bupivacaine-induced cardiac depression is helpful for safe anesthetic management. Bupivacaine is generally used during regional anesthesia with only essential monitoring such as blood pressure and the electrocardiogram (ECG). The bupivacaine infusion reduces cardiac output $(\mathrm{CO})$, which has been associated with an increase in plasma bupivacaine concentration. ${ }^{5}$ Mean arterial blood pressure (MAP) is not useful for the early detection of bupivacaine-induced cardiotoxicity because it is often maintained until the development of cardiovascular collapse, ${ }^{5,6}$ and heart rate (HR) is not correlated with $\mathrm{CO}$ when bupivacaine is administered parenterally in humans. ${ }^{7}$ Although mixed venous oxygen saturation $\left(\mathrm{SvO}_{2}\right)$ is correlated with $\mathrm{CO}$ decrease in the early bupivacaine-induced cardiotoxicity, ${ }^{5}$ a simple and commonly used monitor capable of early detection of bupivacaine-induced cardiac depression would be preferable.

Bupivacaine causes cardiac depression that is associated with conduction block by a cardiac sodium channel blockade. ${ }^{8}$ Bupivacaine also decreases the maximal rate of depolarization in Purkinje fibres. ${ }^{9,10}$ The mean electrical axis of the heart and ECG shape are influenced by the properties of the conduction system and cardiac muscle, and this may manifest differently according to different leads of the ECG. Bupivacaine infusion increased ECG intervals ${ }^{5,11}$ and decreased the R-wave amplitude in lead II. ${ }^{6}$ We assumed that the changes of ECG morphology according to different leads are possible indicators for the early detection of bupivacaine-induced decreases in $\mathrm{CO}$. The purpose of this study is to investigate changes of the ECG variables in leads I, II and III when CO decreases with bupivacaine infusion, and to establish a new variable for detecting early bupivacaine-induced cardiac depression.

\section{Methods}

Our study received approval from the Animal Care and Use Committee of the Seoul National University College of Medicine. Nine male mongrel dogs (19-25 $\mathrm{kg}$ ) were anesthetized with thiopental sodium 10 $\mathrm{mg} \cdot \mathrm{kg}^{-1}$ iv followed by a continuous infusion of 5 $\mathrm{mg} \cdot \mathrm{kg}^{-1} \cdot \mathrm{hr}^{-1}$ sodium pentobarbital. The dogs were placed supinely in a V-shaped operating table with the legs tied to its sides to maintain uniform body and limb position. The trachea was intubated with an internal diameter $7.5 \mathrm{~mm}$ cuffed endotracheal tube. Vecuronium $0.2 \mathrm{mg} \cdot \mathrm{kg}^{-1}$ was injected, and this was followed by $0.02 \mathrm{mg} \cdot \mathrm{kg}^{-1}$ at $30 \mathrm{~min}$ intervals. Mechanical ventilation with $100 \% \mathrm{O}_{2}$ was provided to maintain normocarbia. Normal saline was infused at a rate of $5 \mathrm{~mL} \cdot \mathrm{kg}^{-1} \cdot \mathrm{hr}^{-1}$ throughout the experiment.

The cardiac rhythm and HR were recorded for digital ECG analysis (MAC $8{ }^{\circledR}$, Marquette, Milwaukee, WI, USA) and monitoring (Hewlett-Packard Model 54S, Andover, MA, USA) every five minutes. Percutaneous $20 \mathrm{G}$ polyvinyl catheters were inserted into both femoral arteries to continuously monitor arterial blood pressure and to obtain blood samples. The femoral arterial pressures were recorded at fiveminute intervals during the study. A pulmonary artery catheter (Opticath ${ }^{\circledR}$, P 7110-EH, Abbott, Chicago, IL, USA) was inserted via the external jugular vein and $\mathrm{CO}$ was measured in triplicate using the thermodilution method. Body temperature of the dogs was maintained at 37 to $38^{\circ} \mathrm{C}$ using a heating blanket and warmed fluid. The dogs were stabilized for $30 \mathrm{~min}$ before the start of the bupivacaine infusion.

After having measured the baseline variables, $0.5 \%$ bupivacaine was administered through a peripheral in line at a rate of $0.5 \mathrm{mg} \cdot \mathrm{kg}^{-1} \cdot \mathrm{min}^{-1}$. At the same time, sodium bicarbonate was infused via a pulmonary artery catheter at a rate of 2 to $4 \mathrm{mmol} \cdot \mathrm{kg}^{-1} \cdot \mathrm{hr}^{-1}$ to maintain the arterial $\mathrm{pH}$ at 7.35 to 7.45 . Bupivacaine was administered continuously for $30 \mathrm{~min}$; this was defined as the early period of bupivacaine cardiotoxicity based upon a previous study. ${ }^{5} \mathrm{CO}, \mathrm{HR}, \mathrm{MAP}$, mean pulmonary artery pressure (MPAP), pulmonary artery wedge pressure (PAWP) and central venous pressure (CVP) were measured every five minutes for $30 \mathrm{~min}$ after the start of the bupivacaine infusion. At the same time, the PR interval, QRS duration and the QTc interval were digitally measured with a resting ECG analysis system. $\mathrm{R}$-wave, $\mathrm{S}$-wave, and T-wave amplitudes in leads I, II and III were measured during the expiratory period at five-minute intervals. The electrical axes of the heart were calculated by the sum of leads I and III vectors in the hexaxial reference system. Hemoglobin concentration was measured at the baseline, and arterial blood samples were obtained every ten minutes for blood gas analysis, and measurement of serum $\mathrm{Na}^{+}, \mathrm{K}^{+}$and plasma bupivacaine concentrations. Blood samples for the bupivacaine concentration assay were centrifuged at $2500 \mathrm{rpm}$ for $20 \mathrm{~min}$ and the plasma was stored at $-20^{\circ} \mathrm{C}$ until the time of analysis. The bupivacaine concentration was measured by high-performance liquid chromatography using an ultraviolet detector at a wavelength of $204 \mathrm{~nm}$ with a low limit of sensitivity of $4 \mathrm{ng} \cdot \mathrm{mL}^{-1}$. $^{12}$ 
TABLE I Hemodynamic variables and bupivacaine concentration during the experiment

\begin{tabular}{|c|c|c|c|c|c|c|c|c|}
\hline & Baseline & $5 \min$ & $10 \mathrm{~min}$ & $15 \mathrm{~min}$ & $20 \mathrm{~min}$ & $25 \mathrm{~min}$ & $30 \mathrm{~min}$ & $\begin{array}{l}\text { Pearson's coefficient } \\
\text { with CO }(n=63)\end{array}$ \\
\hline $\mathrm{CO}\left(\mathrm{L} \cdot \mathrm{min}^{-1}\right)$ & $4.1 \pm 1.1$ & $3.3 \pm 1.2^{*} \dagger$ & $2.7 \pm 0.9^{*} \dagger$ & $2.5 \pm 0.9^{*} \dagger$ & $2.3 \pm 1.0^{*} \dagger$ & $1.9 \pm 0.9^{*} \dagger$ & $1.6 \pm 1.0^{*} \dagger$ & 1 \\
\hline HR (beats. $\min ^{-1}$ ) & $134 \pm 25$ & $123 \pm 22^{*} \dagger$ & $117 \pm 18^{*}$ & $119 \pm 13^{*}$ & $119 \pm 10^{*}$ & $114 \pm 12^{*} \dagger$ & $104 \pm 19^{*} \dagger$ & $0.689 \ddagger$ \\
\hline $\mathrm{MAP}(\mathrm{mmHg})$ & $113 \pm 9$ & $120 \pm 13^{*} \dagger$ & $118 \pm 9$ & $119 \pm 12$ & $114 \pm 11$ & $109 \pm 12 \dagger$ & $96 \pm 17^{*} \dagger$ & 0.123 \\
\hline $\mathrm{MPAP}(\mathrm{mmHg})$ & $15 \pm 2$ & $15 \pm 2$ & $18 \pm 3^{*} \dagger$ & $20 \pm 4^{*} \dagger$ & $20 \pm 4^{*}$ & $20 \pm 3^{*}$ & $19 \pm 2^{*} \dagger$ & $-0.433 \ddagger$ \\
\hline PAWP (mmHg) & $12 \pm 3$ & $13 \pm 2^{*} \dagger$ & $16 \pm 3^{*} \dagger$ & $17 \pm 4^{*} \dagger$ & $19 \pm 4^{*} \dagger$ & $17 \pm 3^{*}$ & $17 \pm 3^{*}$ & $-0.396 \ddagger$ \\
\hline $\mathrm{CVP}(\mathrm{mmHg})$ & $5 \pm 1$ & $5 \pm 1$ & $6 \pm 1^{*} \dagger$ & $7 \pm 2 *$ & $8 \pm 2^{*} \dagger$ & $8 \pm 2^{*}$ & $8 \pm 2^{*}$ & $-0.601 \ddagger$ \\
\hline $\begin{array}{l}\text { Bupivacaine } \\
\text { concentration } \\
\left(\mu \mathrm{g} \cdot \mathrm{mL}^{-1}\right)\end{array}$ & 0 & & $11.1 \pm 5.4^{*} \dagger$ & & $13.7 \pm 4.8^{*} \dagger$ & & $17.0 \pm 7.6^{*} \dagger$ & $-0.616 \ddagger^{a}$ \\
\hline
\end{tabular}

Values are expressed as means $\pm \mathrm{SD} . \mathrm{CO}=$ cardiac output; $\mathrm{HR}=$ heart rate; $\mathrm{MAP}=$ mean arterial blood pressure; MPAP $=$ mean pulmonary artery pressure; PAWP = pulmonary artery wedge pressure; CVP $=$ central venous pressure. ${ }^{*} P<0.05$ vs baseline; $\dagger P<0.05$ vs previous value; $\ddagger P<0.05$ correlated with CO. ${ }^{\text {a }}$ Pearson’s coefficient between bupivacaine concentration and CO was calculated from $36 n$.

We compared changes with baseline values at fiveminute intervals. Analysis of variance for repeated measures with simple and repeated contrast was used to evaluate the changes over time. Pearson's correlation coefficients for all variables were calculated to test their relationship with $\mathrm{CO}$, and linear regression analysis was performed with the most correlated variable. Probability values $<0.05$ were accepted as significant. SPSS version 11.5 (SPSS Inc., Chicago, IL, USA) was used for statistical analysis.

\section{Results}

The hemoglobin concentration at baseline was $9.2 \pm$ $1.1 \mathrm{~g} \cdot \mathrm{dL}^{-1}$. Arterial blood gas analysis showed a $\mathrm{pH}$ between 7.34 to $7.48, \mathrm{PaCO}_{2} 34$ to $42 \mathrm{mmHg}$, and the $\mathrm{PaO}_{2} 445$ to $521 \mathrm{mmHg}$ during the study. Plasma $\mathrm{Na}^{+}\left(145-152 \mathrm{~mol} \cdot \mathrm{L}^{-1}\right)$ and $\mathrm{K}^{+}\left(3.6-4.4 \mathrm{~mol} \cdot \mathrm{L}^{-1}\right)$ were within accepted physiologic levels throughout the experiment. The bupivacaine infusion was associated with a $20 \%$ decrease in CO $(P<0.05)$ and $8 \%$ decrease in HR from the baseline values $(P<0.05)$ during the first five minutes. MAP slightly increased during the first five minutes and then it remained at baseline values until $30 \mathrm{~min}$. Ten minutes after initiation of the bupivacaine infusion, significant increases were observed for the MPAP $(P<0.05)$. PAWP and CVP increased significantly after five minutes and ten minutes respectively $(P<0.05)$. Mean plasma bupivacaine concentrations increased over time with the bupivacaine infusion (Table I).

No animal had pathologic arrhythmia at baseline. During the bupivacaine infusion, significant changes were observed in the intervals and amplitudes (Figure 1). Significant increases were seen in the PR interval and QRS complex (approximately 13\% and 45\% respectively) within five minutes, and in the QTc

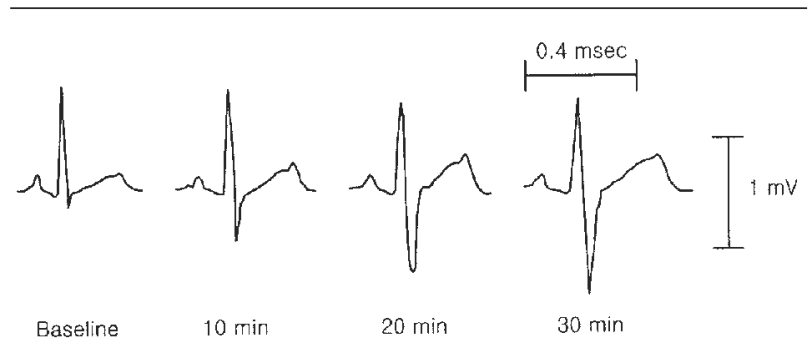

FIGURE 1 Electrocardioraphic changes in lead III induced by bupivacaine infusion

In an experimental dog, the constant rate bupivacaine infusion progressively increased the $S$-wave amplitude $(-0.1 \mathrm{mV}$, $-0.4 \mathrm{mV},-0.9 \mathrm{mV}$ and $-1.05 \mathrm{mV}$ every ten minutes) associated with a progressive decrease in cardiac output (3.4 $\mathrm{L} \cdot \mathrm{min}^{-1}, 2.3 \mathrm{~L} \cdot \mathrm{min}^{-1}, 1.8 \mathrm{~L} \cdot \mathrm{min}^{-1}$ and $\left.1.6 \mathrm{~L} \cdot \mathrm{min}^{-1}\right)$. The changes of $\mathrm{R}$-wave and $\mathrm{T}$-wave amplitudes were $1.0 \mathrm{mV}$, $0.95 \mathrm{mV}, 0.95 \mathrm{mV}$ and $0.9 \mathrm{mV}$, and $0.15 \mathrm{mV}, 0.3 \mathrm{mV}$, 0.45 and $0.45 \mathrm{mV}$ respectively.

interval after ten minutes. The mean electrical axis of the heart deviated to the left and ECG shape changed differently according to leads. The R-wave amplitude in lead II showed a difference from the baseline value after $20 \mathrm{~min}$. The $\mathrm{R}$-wave amplitude in lead III increased at five minutes and it returned to the baseline value after ten minutes. S-wave amplitudes in leads I and II differed significantly from baseline values after ten minutes, and the $S$-wave amplitude in lead III increased twice during the first five minutes. Significant increases were observed in the T-wave amplitudes in leads II and III at five minutes (about $52 \%$ and $72 \%$ respectively), (Table II). Amongst the variables which changed during the first five minutes, 
TABLE II ECG parameters in leads I, II and III during the experiment

\begin{tabular}{|c|c|c|c|c|c|c|c|c|}
\hline & Baseline & $5 \mathrm{~min}$ & $10 \mathrm{~min}$ & $15 \mathrm{~min}$ & $20 \mathrm{~min}$ & $25 \mathrm{~min}$ & $30 \mathrm{~min}$ & $\begin{array}{l}\text { Pearson's coefficient } \\
\text { with } C O(n=63)\end{array}$ \\
\hline Heart axis $\left({ }^{\circ}\right)$ & $72 \pm 12$ & $70 \pm 14$ & $66 \pm 16^{*} \dagger$ & $61 \pm 16^{*}$ & $48 \pm 32 *$ & $36 \pm 48^{*}$ & $30 \pm 5 l^{*}$ & $0.625 \ddagger$ \\
\hline $\mathrm{PR}(\mathrm{msec})$ & $114 \pm 14$ & $129 \pm 19^{*} \dagger$ & $131 \pm 14^{*}$ & $136 \pm 14^{*}$ & $138 \pm 11^{*}$ & $150 \pm 19^{*} \dagger$ & $155 \pm 14^{*} \dagger$ & $-0.589 \ddagger$ \\
\hline QRS (msec) & $38 \pm 6$ & $55 \pm 15^{*} \dagger$ & $66 \pm 12^{*} \dagger$ & $76 \pm 19^{*}$ & $85 \pm 22^{*} \dagger$ & $91 \pm 25^{*}$ & $103 \pm 20^{*} \dagger$ & $-0.577 \ddagger$ \\
\hline QTc (msec) & $349 \pm 21$ & $361 \pm 25$ & $372 \pm 27^{*} \dagger$ & $383 \pm 39 *$ & $392 \pm 37^{*} \dagger$ & $393 \pm 41^{*}$ & $404 \pm 45^{*}$ & $-0.209^{\top}$ \\
\hline $\mathrm{RI}(\mathrm{mV})$ & $0.46 \pm 0.26$ & $0.53 \pm 0.29$ & $0.52 \pm 0.34$ & $0.51 \pm 0.32$ & $0.49 \pm 0.34$ & $0.39 \pm 0.24 \dagger$ & $0.36 \pm 0.20$ & $-0.338 \ddagger$ \\
\hline $\mathrm{SI}(\mathrm{mV})$ & $-0.07 \pm 0.13$ & $-0.09 \pm 0.13$ & $-0.12 \pm 0.15^{*}$ & $-0.12 \pm 0.15^{*}$ & $-0.12 \pm 0.15^{*}$ & $-0.12 \pm 0.15^{*}$ & $-0.12 \pm 0.11$ & $-0.415 \ddagger$ \\
\hline $\mathrm{TI}(\mathrm{mV})$ & $0.06 \pm 0.06$ & $0.07 \pm 0.08$ & $0.08 \pm 0.09$ & $0.06 \pm 0.09$ & $0.05 \pm 0.12$ & $0.07 \pm 0.07$ & $0.08 \pm 0.07$ & -0.051 \\
\hline RII (mV) & $1.31 \pm 0.28$ & $1.35 \pm 0.34$ & $1.28 \pm 0.32$ & $1.24 \pm 0.33$ & $1.16 \pm 0.35^{*}$ & $1.11 \pm 0.29^{*}$ & $1.10 \pm 0.30^{*}$ & $0.355 \ddagger$ \\
\hline SII $(\mathrm{mV})$ & $-0.12 \pm 0.12$ & $-0.20 \pm 0.11$ & $-0.27 \pm 0.11^{*} \dagger$ & $-0.38 \pm 0.17^{*} \dagger$ & $-0.43 \pm 0.23 *$ & $-0.52 \pm 0.29^{*} \dagger$ & $-0.62 \pm 0.31 * \dagger$ & $0.579 \ddagger$ \\
\hline TII $(\mathrm{mV})$ & $0.25 \pm 0.07$ & $0.38 \pm 0.16^{*} \dagger$ & $0.43 \pm 0.18^{*} \dagger$ & $0.46 \pm 0.18^{*} \dagger$ & $0.50 \pm 0.22 *$ & $0.53 \pm 0.26^{*}$ & $0.54 \pm 0.25^{*}$ & -0.184 \\
\hline RIII (mV) & $1.06 \pm 0.33$ & $1.15 \pm 0.37^{*} \dagger$ & $1.10 \pm 0.40$ & $1.11 \pm 0.39$ & $1.04 \pm 0.35 \dagger$ & $1.03 \pm 0.34$ & $1.05 \pm 0.33$ & $0.511 \ddagger$ \\
\hline SIII (mV) & $-0.14 \pm 0.13$ & $-0.28 \pm 0.18^{*} \dagger$ & $-0.38 \pm 0.17^{*} \dagger$ & $-0.53 \pm 0.23^{*} \dagger$ & $-0.62 \pm 0.28^{*} \dagger$ & $-0.71 \pm 0.33^{*}$ & $-0.77 \pm 0.31$ * & $0.751 \ddagger$ \\
\hline TIII $(\mathrm{mV})$ & $0.18 \pm 0.04$ & $0.31 \pm 0.09 * \dagger$ & $0.38 \pm 0.13^{*} \dagger$ & $0.42 \pm 0.14^{*}$ & $0.47 \pm 0.15^{*}$ & $0.48 \pm 0.14^{*}$ & $0.50 \pm 0.20^{*}$ & $-0.286 \ddagger$ \\
\hline
\end{tabular}

Values are expressed as means \pm SD. PR $=$ PR interval; QRS $=$ QRS complex duration; QTc $=$ corrected QT interval; RI $=$ R-wave amplitude in lead I; SI = S-wave amplitude in lead I; TI = T-wave amplitude in lead I; RII = R-wave amplitude in lead II; SII = S-wave amplitude in lead II; TII = T-wave amplitude in lead II; RIII = R-wave amplitude in lead III; SIII = S-wave amplitude in lead III; TIII = T-wave amplitude in lead III; ECG = electrocardiogram; $\mathrm{CO}=$ cardiac output. ${ }^{*} P<0.05$ vs baseline; $\dagger P<0.05$ vs previous value; $\ddagger P<$ 0.05 correlated with $\mathrm{CO}$.

the $S$-wave in lead III showed the closest correlation with $\mathrm{CO}$ (Figure 2).

\section{Discussion}

We performed this study to investigate the hemodynamic and electrophysiologic response associated with $\mathrm{CO}$ changes during bupivacaine-induced cardiac depression in dogs. The results indicate that the change of S-wave amplitude in lead III is closely correlated with the CO decrease observed with bupivacaineinduced cardiac depression. In order to detect early bupivacaine cardiotoxiciy, the variable should change with small amounts of bupivacaine and be well correlated with the resultant CO decrease. S-wave amplitudes in lead III increased by approximately 100\% from the baseline value during the first five minutes, and correlated with a decrease in $\mathrm{CO}$ during the 30 min of bupivacaine infusion. In this respect, the $S$-wave amplitude in lead III may be a useful surrogate marker of impending bupivacaine cardiotoxicity. We infused bupivacaine for $30 \mathrm{~min}$, which was defined as the early phase of bupivacaine cardiotoxicity in a previous study ${ }^{11}$ where dogs receiving $0.5 \%$ bupivacaine at a rate of $0.5 \mathrm{mg} \cdot \mathrm{kg}^{-1} \cdot \mathrm{min}^{-1}$ for $30 \mathrm{~min}$ recovered spontaneously, after the cessation of bupivacaine infusion.

Local anesthetics have been shown to induce an excitement state that increases MAP or HR, and this may complicate interpretations. ${ }^{13}$ In this study, MAP did not decrease during the bupivacaine infusion, as observed in our previous report. ${ }^{5}$ Contrary to another investigation, ${ }^{7} \mathrm{HR}$ decreased with small doses of bupivacaine, which probably resulted from a reduction of the neurologic and hormonal responses of the anesthetized animals. No evidence of seizure activity was observed, nor sudden increases of $\mathrm{HR}, \mathrm{MAP}, \mathrm{CO}$ and motor movement.

Nystrom et al. observed that the R-wave amplitude in lead II correlated with the amount of bupivacaine infused in pigs. ${ }^{6} \mathrm{We}$ also confirmed the lead II R-wave amplitude correlated with $\mathrm{CO}$ during bupivacaineinduced cardiac depression. However, R-wave amplitude in lead II increased modestly within the first five minutes of bupivacaine infusion. In addition we investigated all changes of ECG waves, including the Swave in all bipolar limb leads, and found that amongst the standard leads I, II and III, the S-wave amplitude in lead III most closely correlated with CO changes in dogs with bupivacaine-induced cardiotoxicity.

Although the study was not designed to evaluate mechanisms, the conduction delay or defect accompanied with the left axis deviation may be the reason whereby the $S$-wave amplitude in lead III showed a high correlation with $\mathrm{CO}$ decrease. The orientation of the mean electrical axis is determined by the interaction of three factors: the anatomical position of the heart in the chest, the properties of the cardiac conduction system, and the activation and recovery properties of the myocardium. The major influences on the mean electrical axis are the properties of the conduction system and the cardiac muscle. 


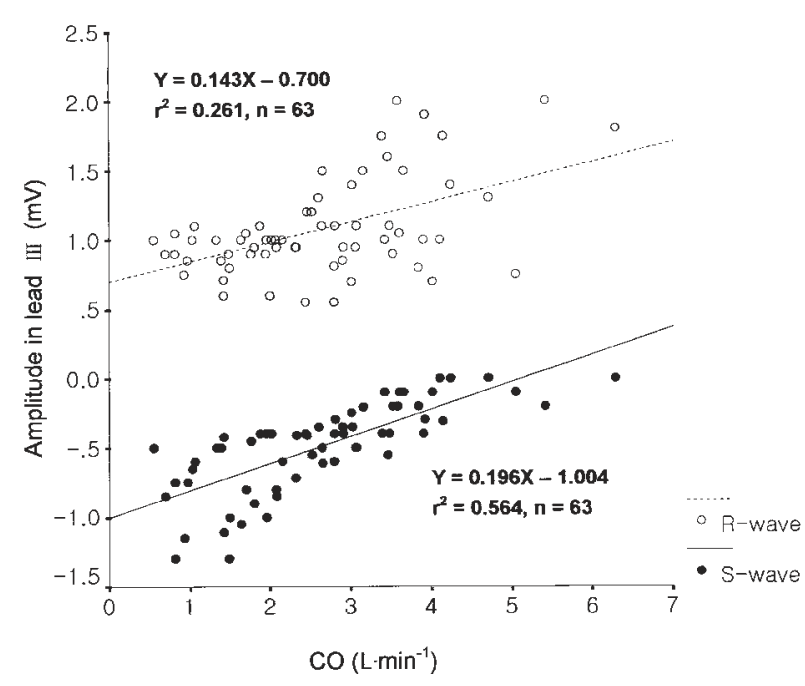

FIGURE 2 Relationship between cardiac output (CO) vs $\mathrm{S}$-wave amplitude or $\mathrm{R}$-wave amplitude in lead III $S$-wave amplitude $\left(P=1.37 \times 10^{-12}\right)$ reflected CO more precisely than $\mathrm{R}$-wave amplitude $\left(P=1.91 \times 10^{-5}\right)$ in dogs with bupivacaine-induced cardiac depression.

Bupivacaine provokes a disturbance of sodium channels throughout the heart, and this leads to decreased conduction speed across the conduction system, or in response to a conduction block. ${ }^{8,14}$ There might be preferential binding sites of bupivacaine within the conducting system. The impaired depolarization of the myocardium associated with the uneven intraventricular conduction defect may change the orientation of electrical heart axis and transform the QRS complex into the decreased $\mathrm{R}$-wave amplitude and increased $S$-wave amplitude with subsequent prolongation of the PR and QRS intervals. Bupivacaine impairs the repolarization by blocking the potassium channels, ${ }^{15}$ and this could possibly affect the T-wave amplitude. Intravascular bupivacaine is associated with increased T-wave amplitude in cats or children. ${ }^{16-18}$ Actually, intravascular injection of lidocaine $\left(3.6 \mathrm{mg} \cdot \mathrm{kg}^{-1}\right)$ plus bupivacaine $\left(0.9 \mathrm{mg} \cdot \mathrm{kg}^{-1}\right)$ without epinephrine increased not only $\mathrm{T}$-wave but also $\mathrm{S}$-wave in lead II in a sevoflurane-anesthetized child. ${ }^{18}$

This study was performed in anesthetized and ventilated dogs that received continuously bicarbonate and $100 \% \mathrm{O}_{2}$, where cardiotoxicity was induced by a continuous infusion of bupivacaine. Accordingly, there may be some limitations in translating our results directly to human subjects. ECG data from dogs have relatively larger variation than that of humans. Second, the fixed rate infusion of bupivacaine produces differences between plasma concentration and effect site concentration for relatively brief (30 $\min$ ) infusions. Finally, anesthesia may obliterate the neurologically mediated cardiovascular response and central nervous system toxic symptoms that precede the cardiovascular response. Despite these limitations, it is our view that careful observation of the ECG is a practical and simple method for detecting early bupivacaine-induced cardiotoxicity. In conclusion, our results suggest a potential clinical application for choosing the lead III S-wave as a surrogate marker of early bupivacaine-induced cardiotoxicity.

\section{References}

1 Albright $G A$. Cardiac arrest following regional anesthesia with etidocaine or bupivacaine (Editorial). Anesthesiology 1979; 51: 285-7.

2 Marx GF. Cardiotoxicity of local anesthetics-the plot thickens. Anesthesiology 1984; 60: 3-5.

3 Feldman HS, Arthur GR, Pitkanen M, Hurley R, Doucette AM, Covino BG. Treatment of acute systemic toxicity after the rapid intravenous injection of ropivacaine and bupivacaine in the conscious dog. Anesth Analg 1991; 73: 373-84.

4 Chadwick HS. Toxicity and resuscitation in lidocaineor bupivacaine-infused cats. Anesthesiology 1985; 63: 385-90.

5 Kim JT, Rhee KY, Bahk JH, et al. Continuous mixed venous oxygen saturation, not mean blood pressure, is associated with early bupivacaine cardiotoxicity in dogs. Can J Anesth 2003; 50: 376-81.

6 Nystrom EU, Heavner JE, Buffington CW. Blood pressure is maintained despite profound myocardial depression during acute bupivacaine overdose in pigs. Anesth Analg 1999; 88: 1143-8.

7 Hasselstrom LJ, Mogensen T, Keblet H, Christensen NJ. Effects of intravenous bupivacaine on cardiovascular function and plasma catecholamine levels in humans. Anesth Analg 1984; 63: 1053-8.

8 Clarkson CW, Hondeghem LM. Mechanism for bupivacaine depression of cardiac conduction: fast block of sodium channels during the action potential with slow recovery from block during diastole. Anesthesiology 1985; 62: 396-405.

9 Lynch C III. Depression of myocardial contractility in vitro by bupivacaine, etidocaine, and lidocaine. Anesth Analg 1986; 65: 551-9.

10 Arlock P. Actions of three local anaesthetics: lidocaine, bupivacaine and ropivacaine on guinea pig papillary muscle sodium channels (Vmax). Pharmacol Toxicol 1988; 63: 96-104. 
11 Cho HS, Lee JJ, Chung IS, Shin BS, Kim JA, Lee KH.

Insulin reverses bupivacaine-induced cardiac depression in dogs. Anesth Analg 2000; 91: 1096-102.

12 Emara S, Khedr A, Askal H. Rapid and specific precolumn extraction high-performance liquid chromatographic assay for bupivacaine in human serum. Biomed Chromatogr 1996; 10: 131-4.

13 Rutten AJ, Nancarrow C, Mather LE, Ilsley AH, Runciman WB, Upton RN. Hemodynamic and central nervous system effects of intravenous bolus doses of lidocaine, bupivacaine, and ropivacaine in sheep. Anesth Analg 1989; 69: 291-9.

14 de La Coussaye JE, Brugada J, Allessie MA. Electrophysiologic and arrhythmogenic effects of bupivacaine. A study with high-resolution ventricular epicardial mapping in rabbit hearts. Anesthesiology 1992; 77: 132-41.

15 Castle NA. Bupivacaine inhibits the transient outward $\mathrm{K}^{+}$current but not the inward rectifier in rat ventricular myocytes. J Pharmacol Exp Ther 1990; 255: 1038-46.

16 Heavner JE. Cardiac dysrhythmias induced by infusion of local anesthetics into the lateral cerebral ventricle of cats. Anesth Analg 1986; 65: 133-8.

17 Fisher QA, Shaffner DH, Yaster M. Detection of intravascular injection of regional anaesthetics in children. Can J Anaesth 1997; 44: 592-8.

18 Tanaka $M$, Nitta $R$, Nishikawa T. Increased T-wave amplitude after accidental intravascular injection of lidocaine plus bupivacaine without epinephrine in sevoflurane-anesthetized child. Anesth Analg 2001; 92: 915-7. 